\title{
Cassirer and Bohr on Intuitive and Symbolic Knowledge in Quantum Physics*
}

\author{
Hernán PRINGE
}

Received: 12.12 .2013

Final version: 31.03 .2014

BIBLID [0495-4548 (2014) 29: 81; pp. 417-429]

DOI: $10.1387 /$ theoria. 10513

ABSTRACT: This paper compares Cassirer's and Bohr's views on symbolic knowledge in quantum physics. Although both of them consider quantum physics as symbolic knowledge, for Cassirer this amounts to a complete renunciation to intuition in quantum physics, while according to Bohr only spatio-temporal images may provide the mathematical formalism of the theory with physical reference. We show the Kantian roots of Bohr's position and we claim that his Kantian concept of symbol enables Bohr to account for the sensible content of quantum theory as well as for its systematic relation to classical physics.

Keywords: Cassirer; Bohr; symbol; intuition; quantum physics.

RESUMEN: En este artículo se comparan las concepciones de Cassirer y Bohr del conocimiento simbólico de la física cuántica. Aunque ambos consideran a la física cuántica un conocimiento simbólico, para Cassirer esto conlleva una renuncia total a la intuición en física cuántica, mientras que para Bohr sólo las imágenes espacio-temporales pueden proporcionar al formalismo matemático de la teoría una referencia física. Mostraremos las raíces kantianas de la posición de Bohr y afirmaremos que esta noción kantiana de símbolo permite a Bohr explicar el contenido sensible de la teoría cuántica, así como su relación sistemática con la física clásica.

Palabras clave: Cassirer; Bohr; símbolo; intuición; física cuántica.

In this paper I aim at comparing the epistemological function which Cassirer assigns to sensible intuition in quantum physics with that assigned by Bohr. I shall show that both agree on the impossibility of considering sensible representations as direct exhibitions in intuition of atomic objects and processes. In this sense, both consider our knowledge of the quantum realm to be symbolic. However, while for Cassirer this entails that spatio-temporal images play no substantial role in quantum physics, Bohr maintains that these images provide the mathematical formalism of the theory with reference to the physical world. Instead of celebrating an alleged abandonment of sensible representations, as Cassirer does, Bohr claims that spatio-temporal pictures should be retained in order to exhibit quantum objects and processes indirectly in intuition. In this way, while Cassirer states that it is only by completely renouncing sensible representations in quantum physics that we may gain systematicity in our physical knowledge, Bohr is able to account for the sensible content of quantum theory as well as for its systematic relation to classical physics.

\footnotetext{
${ }^{*}$ This article is part of the proyect FONDECYT Nº1140112, Government of Chile.
} 
In the following, I first reconstruct Cassirer's view on the role of sensible intuition in modern science. Then, I turn to Bohr's account of the epistemological function of classical pictures in quantum physics. Finally, I consider the problem of the systematic relationship between our knowledge of the classical and the quantum realm.

\section{Cassirer on Intuitive and Symbolic Knowledge in Modern Science}

Cassirer (1956, 130f) conceives the novel epistemological issues raised by quantum physics as following the general tendency already shown by the development of classical physics. The knowledge of nature provided by modern science is determined by the progressive abandonment of the concept of substance in favour of the concept of function. This process leads us to refrain from any claimed similarity between concepts and things. Whereas in the substantialistic conception one presupposes "the existence of things in their inexhaustible multiplicity, and the power of the mind to select from this wealth of particular existences those features that are common to several of them" $(1923,4)$, according to the functionalistic view objects are no longer the starting point but rather the end goal of our considerations. Our knowledge of nature progresses by condensing into laws and thus into objective statements the empirical data gained through observations and measurements: "Objectivity, or objective reality, is attained only because and insofar as there is conformity to law-not vice versa" (1956, 132). It is precisely by rejecting any similarity between concepts and things that modern science is able to become aware of the "lawfulness of being and events" (1957, vol. 3, 452). This means that modern science becomes "truly systematic only by resolving to become symbolic in the strict sense" (ibid.).

It is not our aim to carry out here a general discussion on Cassirer's concept of symbol. ${ }^{1}$ We would like to point out just one particular aspect of Cassirer's position, namely that symbolic knowledge is to be opposed with intuitive knowledge. By maintaining this opposition, the Neo-Kantian Cassirer moves away from the Kantian doctrine and approaches a Neo-Leibnizian stance. ${ }^{2}$ Let us briefly consider this issue. ${ }^{3}$

In a very well-known passage, Leibniz explicitly establishes the opposition between symbolic and intuitive knowledge. Leibniz claims: "All knowledge is either obscure or clear, and clear knowledge is either confused or distinct, the distinct in its turn is either inadequate or adequate, and again symbolic or intuitive" $(1985,3) .{ }^{4}$

Kant firmly rejects this view and affirms that "the intuitive in cognition must be contrasted to the discursive (not to the symbolic)" (2000, $226[\mathrm{KU}, \mathrm{AA} \mathrm{V}, 352]$ ). Symbolic knowledge is rather a kind of intuitive cognition, which takes place when a concept is exhibited in intuition in a mediate manner, by means of an analogy. If, on

\footnotetext{
${ }^{1}$ On this issue see Ferrari (2003).

${ }^{2}$ This point is underlined by Ferrari in his 2003, $163 \mathrm{ff}$.

${ }^{3}$ On the Leibnizian and Kantian traditions in the modern history of the concept of symbol, see Ferrari (2002).

${ }^{4}$ See also Wolff (1720, \$§ 316 -324). On Leibniz’s concept of symbol see Krämer (1991; 1992).
} 
the contrary, a concept is immediately exhibited in intuition, this intuitive representation is not symbolic but schematic.

As we said, with his doctrine of symbolic knowledge Cassirer gets closer to Leibniz than to Kant. However, a crucial difference should be indicated. According to Leibniz, the most perfect knowledge is not symbolic knowledge, but the one which is "both adequate and intuitive" $(1985,3)$. Leibniz considers as most perfect the knowledge provided by an intellectual intuition which enables us to simultaneously conceive the manifold of concepts present in a composite one. To the contrary, Cassirer favours symbolic over intuitive cognition, for the latter is now provided by a sensible intuition, dependent on space, time and empirical determinations.

Cassirer claims that the development of modern natural philosophy may be characterized as a progressive transition from intuitive to symbolic knowledge. The first milestone on this road is Descartes. According to Cassirer, Descartes substituted with pure representations those elements present in Aristotelian physics that were related to sensation. Thereby Descartes conceived a true understanding of nature as depending on the condition that we represent the material fullness and diversity of nature "by a diversity of form, a geometrical schematism" (1957, vol. 3, 455). The key to a true insight into the lawfulness of nature is not to be found in sensation but in pure space.

But, for Cassirer, this Cartesian position was soon overcome by Leibniz. The form on which physical knowledge is ultimately grounded is not spatial but logical. If we are to obtain true knowledge of nature, then not only the sensuous must be disregarded: intuitive images, even non-empirical ones, must be dismissed altogether. ${ }^{5}$ The most basic propositions about reality are rather grounded on mere intellectual truths.

By emancipating our knowledge from sensible intuition, Leibniz paves the way to a universal cognition of nature. But the history of philosophy followed another path. Kant does not renounce to sensible intuition. On the contrary, he emphatically criticizes Leibniz for having "intellectualized the appearances" by failing to realize that sensible intuitions are not merely obscure and confuse representations that the understanding may make clear and distinct. Sensibility is rather a "special source of representations," as original as understanding, with which the latter must cooperate in order to "judge about things with objective validity" (1998, 372 [A271/B327]). However, Cassirer questions this Kantian vindication of sensible knowledge. ${ }^{6}$ With the introduction of Kant's concept of pure intuition, Cassirer maintains, "a peculiar reversal in the progress of philosophical principles" (1957, vol. 3, 458; my italics) took place.

According to Cassirer, Kant develops his doctrine of sensibility as a moment of the foundation of Newtonian mechanics. Such foundation is carried out following what Neo-Kantians call the transcendental method. ${ }^{7}$ This method consists in taking a fact as

\footnotetext{
5 "A true theory of nature [...] could be achieved only if we learned to disregard both barriers, the sensuous as well as the intuitive" (1957, vol. 3, 456).

${ }^{6}$ On this issue, see Friedman $(2000,108 \mathrm{ff})$.

${ }^{7}$ It is worth noting that the expression 'transcendental method' is not to be found in Kant's texts. See Baum (1980).
} 
point of departure of the philosophical investigation, which searches for the conditions of the possibility of that fact. In this case, Euclidean geometry and Newtonian physics are the assumed facts. However, if these facts are modified, so are their conditions of possibility. Transcendental philosophy faces precisely such situation with the discovery of non-Euclidean geometry and the birth of the theory of relativity. Regarding the former, Cassirer states:

Here [in Kant], then, "pure sensibility" has acquired a position in the total structure of mathematics very different from that which it occupied for Leibniz. Sensibility has ceased to be a mere means of representation, as in Leibniz, and has become an independent ground of knowledge: intuition has now achieved a grounding, legitimizing value. For Leibniz the sphere of intuitive knowledge, referring to the objective combination of ideas, is separate from the sphere of symbolic knowledge, in which we have to do not with the ideas themselves but with the signs that represent them: but the intuition to which he goes back does not stand in opposition to the logi$\mathrm{cal}$; rather it comprises both the logical and the mathematical as special forms. For Kant, however, the dividing line does not pass between intuitive and symbolic thinking, but rather between the discursive concept and "pure intuition," and the meaning of mathematics can only be provided by, and grounded in, the latter.

In this methodological divergence it seems clear that modern mathematics has followed the road indicated by Leibniz rather than that suggested by Kant. This has followed particularly from the discovery of non-Euclidean geometry. The new problems growing out of this discovery have turned mathematics more and more into a hypothetical-deductive system, whose truth-value is grounded purely in its inner logical coherence and consistency, and not in any material, intuitive statements. (1957, vol. 3, 363-64)

Regarding the theory of general relativity, Cassirer indicates that this theory has put into question the logical priority which, according to the Kantian doctrine of space and time, these pure forms of sensibility have in respect to the matter given in them. For Cassirer, this calls for a thorough revision of Kant's doctrine of sensibility:

The axiom that space itself and what fills it, what is substantial and real in it, are separate, that they may be split conceptually into two sharply divided modes of being, is taken from the system of classical mechanics. But with this of course Kant's theory of pure intuition and the whole relation he sets up between the transcendental analytic and the transcendental aesthetic, runs into a difficulty which was bound to become apparent as soon as this axiom itself began to be questioned-as soon as the theory of classical mechanics gave way to the general theory of relativity. (ibid., 459) 8

More generally, the new theories in physics show that symbolic representations must gradually take the place of intuitive pictures. Against the Kantian defense of the necessary role of sensible intuition in knowledge, Cassirer argues that "physics has definitively left the realm of representation and of representability in general for a more abstract realm" (ibid., 467).9

${ }^{8}$ For a recent discussion on Cassirer's position about the problem of space, see Neuber (2012).

9 On Cassirer's philosophy of physics, see Gawronsky (1949), von Strauß und Torney (1956), Hübner (1963) and especially Schmitz-Rigal (2002).

Theoria 81 (2014): 417-429 
This renunciation to intuitive representations can paradigmatically be found in quantum theory:

[Bohr] expressed the conviction that the general problem of the quantum theory was not concerned with a modification of mechanical and electrodynamic theories that could be explained on the basis of ordinary physical concepts but involved a radical denial of the space-time ideas by means of which a description of natural phenomena had previously been attempted. Atomic physics cannot be constructed 'without resignation of the wish for sensuous presentation.' $(1950,116)$

In view of this, Cassirer argues that we would better content ourselves with the mathematical formulation of the laws of the theory and refrain from any exhibition of them in intuition: "The more the conceptual determination progresses, the less it proves possible to fix its results in simple particular visual images. We have to be satisfied with determination by means of laws and must forego any clarification through models" $(1956,144)$.

Moreover, Cassirer claims that this renunciation of intuitiveness does not amount to a renunciation of objectivity in our physical knowledge, because, as we have seen, this objectivity is guaranteed by the mere lawlikeness of the theory: "But true physical objectivity is here not diminished but increased, for it must never be sought in the direction of 'naive' things, but rather in the direction of critical laws" (ibid.). ${ }^{10}$

In the following section we shall come back to Bohr's view, according to which quantum physics does not provide us with spatio-temporal images of natural objects and processes. However, we shall see that, precisely for this reason and in contradiction to Cassirer, Bohr maintains that the physical reference of quantum theory depends on classical descriptions of measurements results, which do provide us with spatio-temporal images.

\section{Bobr on Intuitive and Symbolic Knowledge in Quantum Theory}

Just as Cassirer, Bohr considers physical knowledge to be symbolic. But we should distinguish two senses in which this symbolic character of physics is understood by Bohr. In the first place, science in general and physics in particular provide us with symbolic knowledge because scientific concepts do not portray or depict reality. Their function is rather to bring about order among appearances, connecting them in a uni-

${ }^{10}$ According to Cassirer, the lawlikeness of physical knowledge gets specified in three different types of statements: the statements of measurement results, the statements of laws and the statements of principles. These statements are arranged into a system of experience invariants, being the principle of causality the ultimate condition upon which such system rests (1956, $29 \mathrm{ff})$. An analysis of this issue is carried out in Pringe (2014). In 1910 Cassirer maintains that "the critical theory of experience would constitute the universal invariant theory of experience" $(1923,268)$. In 1936 Cassirer states that the development of modern physics has done nothing but confirm this view (1956, xxiii). He affirms that the role of invariants in physics, which he established in 1910 only by means of his analysis of classical physics, corresponds to "the program of modern theoretical physics, as presented for instance by P. A. Dirac in his Principles of Quantum Mechanics" $(1956,138)$. Also the theory of relativity confirms those early results of a critical theory of experience $(1923,379)$. For an analysis of Cassirer's interpretation of relativity theory, see Ryckman (2005). 
fied experience as extended and interconnected as possible. ${ }^{11}$ The purpose of science "is not to disclose the real essence of the phenomena but only to track down, so far as it is possible, relations between the manifold aspects of experience" $(1934,18)$. This is particularly the case of physics. Physics does not study "something a priori given," since physics is just a method "for ordering and surveying human experience" (1963, 10). Quantum and classical physics are symbolic in this sense.

At this point, Bohr would agree with Cassirer, who states that scientific concepts "are valid, not in that they copy a fixed given being, but in so far as they contain a plan for possible constructions of unity, which must be progressively verified in practice, in application to the empirical material" $(1923,322)$.

In fact, Kramers recalls that "Bohr has expressed himself in discussions somewhat as follows: classical physics and the quantum theory, taken as descriptions of nature, are both caricatures" (quoted in Honner 1987, 158). The objective validity of science does not depend on the existence of a reality to be copied by our concepts, but rather on the "objective determinateness of the method of experience" $(1923,322)$. Bohr would have subscribed to this view.

However, there is a second sense in which physics may be considered symbolic knowledge, but this meaning applies only to quantum and not to classical physics. Moreover, in this case Bohr's concept of symbol differs from Cassirer's, because symbolic knowledge is not to be opposed with intuitive cognition. In this second sense, symbolic knowledge is the cognition of what cannot be directly exhibited in intuition. Since atomic objects and processes cannot simultaneously satisfy the demands of spatio-temporal coordination and the claim of causality, atomic objects and processes cannot be directly exhibited in intuition and their knowledge is thus symbolic. Classical physics is not symbolic knowledge in this restricted sense.

In this connection, an epistolary exchange between Bohr and Christian Møller is particularly relevant. Møller asks Bohr explicitly about the meaning of the word 'symbolic':

The question at stake is what one really understands under the word 'symbolic'-what does it mean that, e.g., the representation of a free particle by means of de Broglie waves is only a symbolic representation?" (Møller to Bohr, 10.06.28; quoted in Stolzenburg 1977, 244; my translation)

But even more important to our discussion is that Møller, after acknowledging that all the signs we use to describe nature are symbols, poses the crucial question:

What does it mean that some [signs] are more symbolic than others [?] (Møller to Bohr, 10.06.28; quoted in Stolzenburg 1977, 244; my italics and translation)

In other words, he demands for an explanation of the specific symbolic character of quantum theory, that distinguishes it from classical physics.

In his response, Bohr agrees that both classical and quantum physics make use of symbols. However, he maintains that there is a difference between both symbolisms and that this difference lies in their relation to intuition:

11 "The task of science is both to extend the range of our experience and to reduce it to order" Bohr $(1934,1)$. 
I have only tried to underline the fact that in quantum theory we extensively use the same symbols as in classical theory, what nevertheless does not allow us to overlook the big difference between these theories and makes necessary great caution in the application of the forms of intuition to which the classical symbols are linked. ${ }^{12}$

The quantum-mechanical formalism is symbolic because its concepts cannot be represented directly in intuition. This is so even in the case of the wave formalism, where the intuitive elements of the theory may hide the specific symbolic character that distinguishes it from any classical theory:

If one considers the wave theory, its 'intuitiveness' is, however, precisely its strength and its trap at the same time and, by underlying the symbolic character of the approach, I have tried to point out here the great difference from the classical theories due to the quantum postulate, [a difference] that is not always taken sufficiently into account. (ibid.)

In the case of matrix mechanics, to the contrary, there is no doubt about the strict symbolic character of the formalism:

Of course, it is not so easy to run into this danger in the matrix formulation, where rules that differ so much from our usual algebra always make evident to us the peculiar essence of quantum theory; to use the word 'symbolic' for non-commutative algebra is by the way a language usage that goes back much further than quantum theory and it is incorporated in the general mathematical terminology. (ibid.)

As a matter of fact, Bohr underlines the peculiar symbolic character of quantum physics by putting quantum symbols in opposition to classical concepts. The latter can be exhibited in spatio-temporal pictures, while the former cannot. ${ }^{13}$

But this sharp distinction between classical and quantum physics is followed by a positive determination of their relationship: classical concepts symbolize atomic objects and processes. More concretely, it is by means of the concepts of isolated particle and free radiation that we exhibit quantum processes indirectly in intuition. ${ }^{14}$ These concepts are classical, since "such concepts as corpuscle and wave are only well defined within the scope of classical physics, where, of course, light and electrons are electromagnetic waves and material corpuscles respectively" (1932, 48). For this reason, "phrases such as 'the corpuscular nature of light' or 'the wave nature of electrons' are ambiguous" (ibid.). This means that we are thereby not claiming that, e.g., electrons are waves, but just that they behave as if they were waves. ${ }^{15}$ We establish a

12 Bohr to Møller, 14.06.28 (quoted in Stolzenburg 1977, 245-46; my translation). Even though the 'old quantum theory' should be distinguished from 'quantum mechanics', Bohr still uses the expression 'quantum theory' after the establishment of quantum mechanics, as it is clear in this passage. For Bohr, wave and matrix mechanics are just two different formulations of the same (quantum) theory.

${ }^{13}$ This is particularly stressed by Chevalley in her (1994, 35ff).

14 "Hitherto we have only regarded certain general features of the quantum problema. This situation implies, however, that the main stress has to be laid on the formulation of the laws governing the interaction between the objects which we symbolize by the abstractions of isolated particles and radiation" Bohr $(1934,69)$. See Pringe (2008).

15 "The extreme fertility of wave pictures in accounting for the behaviour of electrons must, however, not make us forget that there is no question of a complete analogy with ordinary wave propagation in material media or with non-substantial energy transmission in electromagnetic waves. Just as in the case of radiation quanta, often called 'photons', we have here to do with symbols helpful in the 
certain analogy between the behaviour of atomic objects and classical objects, which enables us to obtain an intuitive albeit indirect representation of the atomic entities.

In order to thoroughly account for the empirical evidence it is necessary to use incompatible classical images to represent atomic objects. For example, electrons behave in some situations as if they were waves, but in some others as if they were corpuscles. These incompatible images, each of which is indispensable for a complete account of the experiments, are called complementary representations. The extension and limits of their valid use is determined by the uncertainty relations set up by Heisenberg. Bohr considers these relations "as a direct expression of the absolute limitation of the applicability of visualizable conceptions in the description of nature" $(1934,114)$. Their specific task "consists in assuring quantitatively the logical compatibility of apparently contradictory laws which appear when we use two different experimental arrangements" $(1937,293)$.

Heisenberg summarizes the situation as follows:

$[F]$ or visualization [of atomic processes] [...] we must content ourselves with two incomplete analogies - the wave picture and the corpuscular picture. The simultaneous applicability of both pictures is thus a natural criterion to determine how far each analogy may be 'pushed' and forms an obvious starting-point for the critique of the concepts which have entered atomic theories in the course of their development, for, obviously, uncritical deduction of consequences from both will lead to contradictions. In this way one obtains the limitations of the concept of a particle by considering the concept of a wave. As N. Bohr has shown, this is the basis of a very simple derivation of the uncertainty relations between co-ordinate and momentum of a particle. In the same manner one may derive the limitations of the concept of a wave by comparison with the concept of a particle. $(1949,11)^{16}$

Briefly, quantum and classical physics provide us with symbolic knowledge because none of them is meant to copy an absolute reality. Their task as scientific theories is rather, using a Kantian expression, to "spell out appearances, so that they can be read as experience" (2002, 105-06 [Prol., AA 4: 312]). But the way in which this task is carried out by each of them is not the same. In classical physics, it is possible to exhibit concepts directly in intuition in order to gain a single and all-encompassing image of nature. To the contrary, in quantum physics, such a single image cannot be obtained. Complementary images should be used so that atomic objects and processes are indirectly exhibited in intuition. This is the specific symbolic character of quantum physics Møller was asking about.

\section{Cassirer's versus Bobr's Symbolism}

Both Cassirer and Bohr stress that quantum concepts cannot be exhibited in intuition in the way classical concepts are. However, while for Cassirer this is nothing but a paradigmatic example of the general tendency of science that progressively gets free from the constraints of sensible intuition, Bohr considers that the impossibility of direct exhibition in intuition sets a crucial problem to any interpretation of quantum

formulation of the probability laws governing the occurrence of the elementary processes which cannot be further analysed in terms of classical physical ideas" $(1932,48)$.

${ }^{16}$ See Heisenberg $(1949,11)$.

Theoria 81 (2014): 417-429 
physics. The point of view of complementarity aims at guaranteeing the sensible content of atomic theory, given the restrictions on intuitive exhibition implied by the quantum postulate. Neither the wave nor the corpuscular theory may receive a direct exhibition in intuition: atomic objects are neither waves nor particles. However, in order to account for the experimental evidence, these complementary images must be used as symbolic representations of atomic objects. Atomic objects behave in certain situations as if they were waves and in other experimental contexts as if they were particles. ${ }^{17}$ Whereas according to Cassirer quantum physics is symbolic knowledge because intuitive images have lost their cognitive value in the atomic realm, Bohr does not reject such value. Rather, these intuitive images enable atomic objects to be indirectly exhibited in intuition. For Bohr, the symbolic knowledge provided by quantum physics is not to be opposed to but is a kind of intuitive knowledge. In this sense, we may determine Cassirer's and Bohr's respective place in the modern history of the concept of symbol: while the neo-Kantian Cassirer puts forward a neo-Leibnizian concept of symbol, Bohr is closer to the Kantian than to the Leibnizian stance. ${ }^{18}$

A further point concerns the relationship between intuitiveness and unification in physical theories. Cassirer maintains that in modern physics "the schematism of images has given way to the symbolism of principles" (1957, vol. 3, 467). As we have already argued, for Cassirer the task of physical theories is not to represent a given reality but to articulate appearances in a unified experience. This is precisely what the development of modern physics shows: "the tendency toward unification has triumphed over the tendency toward representation" (ibid.). Cassirer renounces to intuitiveness in order to achieve unification. To the contrary, Bohr is able to account for the unifying power of quantum physics without renouncing to the demand of intuitiveness. ${ }^{19}$ From the perspective of complementarity, quantum physics brings about systematic unity among incompatible classical pictures, whereas these classical representations, albeit

${ }^{17}$ In a letter to Bohr, Schrödinger protests against such a view: "One may weaken the statements, by saying, e.g., that the collection of atoms 'in certain respects behaves as if ...' and 'in certain respects so as if ...', but this is so to speak merely a juridical expedient that cannot be converted into clear reasoning." Schrödinger to Bohr, 23.10.26 (BCW, vol. 6, 12-3). However, from the viewpoint of complementarity there is no unclear reasoning here, for the way in which the symbols are to be used is precisely determined by the uncertainty relations. Fine quotes this letter and identifies Vaihinger's fictionalism (Vaihinger 1924) as the source of this use of the 'as if idiom. See Fine (2009, 23 and fn. 8). For an overview of the recent discussion on fictionalism in the philosophy of science, see Suárez (2009).

18 See Pringe (2008). The Kantian roots of the Bohrian concept of symbol have also been stressed by Chevalley (see her 1994) who moreover calls the attention to the post-Kantian tradition, in which one may count Goethe, Humboldt, Helmholtz, Hertz and Husserl. See also Brock (2003, 136-39). Chevalley affirms that Bohr's use of symbolism is a kind of heresy for a Kantian, because Kant distinguished sharply between the world of physics and those realms ruled by symbolic presentation (art, teleology, language) $(1995,343)$. However, one may also argue for the necessity of symbolic presentations in quantum physics within the very limits of a Kantian critique of knowledge. See Pringe (2007).

${ }^{19}$ It should be pointed out that Bohr's position also differs from those according to which intuitiveness but not unification may be achieved in physical knowledge. This is the case of, i.e., Cartwright's piecemeal physics (see her 1999). In contrast to Cassirer's and Cartwright's positions, the viewpoint of complementarity enables us to have the best of both worlds: intuitiveness and unification. 
indirectly, provide quantum physics with intuitive content. In this way, Bohr does not oppose unification to intuitiveness in quantum physics. He seeks for the satisfaction of both demands. These are fulfilled simultaneously by means of a complementary symbolism in the Kantian sense.

Moreover, it should be indicated that Cassirer's position leaves the systematic relationship between classical and quantum physics without a satisfactory explanation. Classical and quantum physics may be two different 'symbolic forms', but as long as their reciprocal connection remains obscure, we will be lead to conceive physics, in opposition to Cassirer's own intentions, rather as a mere aggregate of cognitions than as a system. In contradistinction to this, Bohr clearly establishes the specific task of classical and quantum physics in our knowledge of the atomic realm. Classical physics provides us with the intuitive content for this knowledge, while the principles of quantum physics unifies that content in a description of nature "which may be considered as a rational generalization of the causal space-time description of classical physics" $(1934,87)$.

By means of this determination of the epistemological role of classical and quantum physics, the viewpoint of complementarity opens the road to a transcendental interpretation of quantum objectivity that establishes the peculiar character of quantum objects in contradistinction to classical ones. Such interpretation may be sketched as follows. We shall firstly distinguish between the objective validity and the objective reality of a concept. The objective validity of a concept consists in the necessary character of the synthesis which the concept rules. In this way, a synthesis according to an objectively valid concept will be opposed to a contingent association of cognitions. In turn, such synthesis may make possible the objective reference of a sensible manifold or may bring about systematic unity between already objective cognitions. In the first case, we will say that the synthesis has constitutive validity, while in the second case rather regulative validity.

In turn, the objective reality of a concept consists in its reference to an empirical content. A concept with objective reality is to be opposed to an empty or merely formal one. A concept may acquire objective reality directly by means of a schema or indirectly, by means of a symbol. ${ }^{20}$

Quantum objectivity is to be distinguished from classical objectivity both regarding the objective validity and the objective reality of the concept of an object. Firstly, the objective validity of the concept of a classical object rests on its epistemological function of constituting the objectivity of a sensible manifold by ruling a synthesis of this empirical content. To the contrary, the objective validity of the concept of a quantum object consists in its regulative task of bringing about systematic unity among complementary phenomena, the objectivity of which is achieved by the use of

20 "If objective reality is accorded to the concept directly (directe) through the intuition that corresponds to it, i.e., if the concept is immediately presented, this act is called schematism; but if it cannot be presented immediately, but only in its consequences (indirecte), it may be called the symbolization of the concept" (Kant 2002, 370 [FM, AA 20: 275]). 
classical concepts for their description. ${ }^{21}$ Secondly, the concept of a classical object acquires objective reality when an empirical multiplicity is subsumed under the concept by means of a schema. In this way, the concept is exhibited directly in intuition. To the contrary, the concept of a quantum object acquires objective reality by means of an indirect exhibition in intuition, through symbolic analogies.

According to Cassirer, critical philosophy establishes that the two essential moments of knowledge are the demand of objectivity and the demand of systematic unity (1923b, 236). Precisely those are the moments which articulate this distinction of classical and quantum objectivity along Bohrian lines. Classical concepts enable the constitution of empirical data as objective experimental results. For this purpose, classical concepts are directly exhibited in intuition. Rather, the concept of a quantum object plays a regulative role, guaranteeing the systematic unity of classically described complementary phenomena. These phenomena provide the concept of the quantum object with objective reality when they are represented as its symbols.

\section{REFERENCES}

Baum, Manfred. 1980. Methode, tranzendentale. In: Historisches Wörterbuch der Philosophie, ed. Joachim Ritter and Karlfried Günder. Bd. 5, Basel-Stuttgart: Schwabe.

Bohr's Collected Works (BCW). Amsterdam: North-Holland. New York: American Elsevier. 1972 ff.

Bohr, Niels. 1932. Chemistry and the Quantum Theory of Atomic Constitution. In Niels Bohr. 1998. Causality and Complementarity. The Philosophical Writings of Niels Bohr, vol. IV. Woodbridge, Connecticut: Ox Bow Press, 29-61.

-. 1934. Atomic Theory and the Description of Nature, Cambridge: Cambridge University Press.

- 1937. Causality and Complementarity. Philosophy of Science 4: 289-98. (Reprinted in Bohr 1998, 83-91).

- 1958. Atomic Physics and Human Knowledge, New York: John Wiley \& Sons.

- 1963. Essays 1958-1962 on Atomic Physics and Human Knowledge, New York: John Wiley \& Sons.

- 1998. Causality and Complementarity. The Philosophical Writings of Niels Bohr, vol. IV. Woodbridge, Connecticut: Ox Bow Press.

Brock, Steen. 2003. Niels Bobr's Philosophy of Quantum Physics in the Light of the Helmboltzian Tradition of Theoretical Physics. Berlin: Logos.

Cartwright, Nancy. 1999. The Dappled World. A Study of the Boundaries of Science. Cambridge: Cambridge University Press.

Cassirer, Ernst. 1923. Substance and Function and Einstein's Theory of Relativity. Chicago and London: Open Court.

-. 1923b. Die Kantischen Elemente in Wilhelm von Humboldts Sprachphilosophie. In Cassirer 2003, 236-73.

- 1950. The Problem of Knowledge. Philosophy, Science and History since Hegel, New Haven and London: Yale University Press.

—. 1956. Determinism and Indeterminism in Modern Physics, Benfey, T. (trans.), New Haven and London: Yale University Press.

- 1957. The Philosophy of Symbolic Forms, Manheim, R. (transl.), 3 vols., New Haven and London: Yale University Press and Oxford University Press.

—. 2003. Geist und Leben. Leipzig: Reclam.

Chevalley, Catherine. 1994. Niels Bohr's Words and the Atlantis of Kantianism. In Faye, Jan and Henry Folse, eds. 1994. Niels Bohr and Contemporary Philosophy, Dordrecht, Kluwer, 33-55.

${ }^{21}$ In this sense, Bohr claims: "it is decisive to recognize that, however far the phenomena transcend the scope of classical physical explanation, the account of all evidence must be expressed in classical terms" (1958, 39). For a further discussion of this issue see Pringe (2012). 
—. 1995. On Objectivity as Intersubjective Agreement. In Krüger, Lorenz and Falkenburg, Brigitte, eds. 1995. Physik, Philosophie und die Einheit der Wissenschaften. Heidelberg: Spektrum, 332-46.

Ferrari, Massimo. 2002. Sources for the History of the Concept of Symbol from Leibniz to Cassirer. In Ferrari, Massimo and Ion-Olimpiu Stamatescu, eds. 2002, Symbol and Physical Knowledge. Berlin: Springer, 3-32.

-. 2003. Ernst Cassirer. Stationen einer philosophischen Biographie. Von der Marburger Schule zur Kulturphilosophie. Hamburg: Meiner.

Fine, Arthur. 2009. Fictionalism. In Suárez, Mauricio, ed. 2009. Fictions in science: Philosophical Essays on Modeling and Idealization. New York: Routledge, 19-36. [Reprint of: Fine, Arthur. 1993. Fictionalism. Midwest Studies in Philosophy 18: 1-18]

Friedman, Michael. 2000. A Parting of the Ways. Carnap, Cassirer and Heidegger. Chicago: Open Court.

Gawronsky, Dimitry. 1949. Cassirer's Contribution to the Epistemology of Physics. In Schilpp, Paul, ed. 1949. The Philosophy of Ernst Cassirer, 215-38.

Heisenberg, Werner. 1949. The physical principles of the quantum theory. Mineola, N.Y.: Dover.

Honner, John. 1987. The Description of Nature. Niels Bohr and the Philosophy of Quantum Physics. Oxford: Clarendon Press.

Hübner, Kurt. 1963. Cassirers Beitrag zur Philosophie der Physik. Philosophische Rundschau 11 (4): 2-27.

Jammer, Max. 1966. The Conceptual Development of Quantum Mechanics. New York: Mc Graw-Hill.

Kants gesammelte Schriften (AA), Königlichen Preußischen (Deutschen) Akademie der Wissenschaften. Berlin. $1902 \mathrm{ff}$

Kant, Immanuel. 1998. Critique of Pure Reason [Kritike der reinen Vernunft] (1781/1787). Cambridge: Cambridge University Press.

-. 2000. Critique of the Power of Judgment [Kritik der Urteilskraft] (1790). Cambridge: Cambridge University Press.

—. 2002. Theoretical Pbilosophy after 1781. Cambridge: Cambridge University Press.

Krämer, Sybille. 1991. Berechenbare Vernunft. Rationalismus und Kalk.ül im 17. Jahrbundert. Berlin: de Gruyter.

—. 1992. Symbolische Erkenntnis bei Leibniz. Zeitschrift für philosophische Forschung 46: 224-37.

Leibniz, Gottfried Wilhelm. 1985. Monadology and Other Philosopbical Essays. New York: Macmillan.

Neuber, Matthias. 2012. Die Grenzen der Revisionismus. Scblick, Cassirer und das ,Raumproblem'. Wien-New York: Springer.

Pringe, Hernán. 2007. Critique of the Quantum Power of Judgment. A Transcendental Foundation of Quantum Objectivity. Berlin-New York: de Gruyter.

- 2008. Kant and Bohr on Symbolic Knowledge in Quantum Theory. In: Akten des X. Internationalen Kant-Kongresses. Berlin: de Gruvter, 757-67.

—. 2012. La filosofía trascendental y la interpretación de Bohr de la teoría cuántica. Scientiae Studia, 10 (1): 179-94.

—. 2014. Causalidad, invariancia y sistematicidad en el neokantismo de Ernst Cassirer. Forthcoming in Estudios de Filosofía.

Ryckman, Thomas. 2005. The Reign of Relativity. Philosophy in Physics 1915-1925. Oxford: Oxford University Press.

Schmitz-Rigal, Christiane. 2002. Die Kunst des offenen Wissens: Cassirers Epistemologie und Deutung der modernen Physik. Hamburg: Meiner.

Stolzenburg, Klaus. 1977. Die Entwicklung des Bobrschen Komplementaritätsgedankes in den Jabren 1924 bis 1929. Ph.D. Thesis. Stuttgart: Universität Stuttgart (Technische Hochschule).

Strauß und Torney, Lothar von. 1956. Das Komplementaritätsprinzip der Physik in philosophischer Analyse. Zeitschrift für philosophische Forschung 10: 109-29.

Vaihinger, Hans. 1924. The Philosophy of "As If«. A System of the Theoretical, Practical and Religious Fictions of Mankind. New York: Harcout, Brace \& Co.

Wolff, Christian. 1720. Vernünfftige Gedancken von Gott, der Welt, und die Seele des Menschen. Halle: Renger. 
Hernán Pringe earned a Ph.D in Philosophy at the Universität Dortmund. He also holds an M.A. and a M.Sc., both from the Universidad de Buenos Aires. He is currently CONICET Researcher at the Instituto de Filosofía, Universidad de Buenos Aires and is Associate Professor at the Universidad Diego Portales.

Address: Instituto de Humanidades, Universidad Diego Portales. Ejército 260, Santiago, Chile. E-mail: hpringe@gmail.com 